\title{
Effect of Thermocycle and Bonding Agents on the Bond Strength of Titanium-resin Cements
}

\section{Titanyum-rezin Siman Bağlanma Dayanımına Isıl Döngü ile Yaşlandırmanın ve Bonding Ajanlarının Etkisi}

(iD Gülsüm SAYIN ÖZEL1ㄴ, (D Ceyda AKIN², iD Bebek Serra OĞUZ AHMET¹

İstanbul Medipol University Faculty of Dentistry, İstanbul, Turkey

${ }^{2}$ Necmettin Erbakan University Faculty of Dentistry, Konya, Turkey

\begin{abstract}
Objective: This research aimed to evaluate the effect of different resin cement $(\mathrm{RC})$ types, compare the effect of surface treatments and bonding applications and evaluate the effect of thermal cycling on bond strengths to Titanium (Ti) surfaces.
\end{abstract}

Methods: A total of $240 \mathrm{Ti}$ discs $(10 \times 3 \mathrm{~mm})$ were randomly divided into two groups. Half of the specimens were sandblasted with 110 $\mu \mathrm{m} \mathrm{Al}_{2} \mathrm{O}_{3}$ particles, whereas the other half had no surface treatments (non-treated). Both sandblasted and non-treated specimens of each surface treatment type were divided into five subgroups, which received one of the following surface conditions and luting selfadhesive resin cement: (a) Panavia SA Cement, (b) Clearfil SE Bond + Panavia SA Cement, (c) RelyX U200, (d) Single Bond Universal + RelyX U200 and (e) MIS Crown Set Cement. A mould with a 4-mm diameter and 2-mm thickness was applied to the central region of the specimens. Each group was divided into subgroups, according to whether performing thermocycling or not. The shear bond tests were conducted at a crosshead speed of $1 \mathrm{~mm} / \mathrm{min}$. Data (N) were analysed using one-way analysis of variance and Tukey's honestly significant difference tests $(\mathrm{p}<0.05)$.

Results: The sandblasted + bonding agent groups provided higher shear bond strength than the non-treated groups for all RC types $(\mathrm{p}<0.05)$. Sandblasted Clearfil SE Bond + Panavia SA Cement (non-thermocycled) showed the highest values $(182.761 \pm 41.55)$, whereas the MIS Cement (17.681 \pm 9.33$)$ and Panavia SA Cement

\section{ÖZ}

Amaç: Bu çalışmanın amacıfarklı rezin simanların, kumlama yüzey işleminin, bonding ajanlarının ve yaşlandırmanın Titanyum (Ti)rezin siman (RS) arasındaki makaslama bağlanma dayanımına etkisinin değerlendirilmesidir.

Yöntemler: İki yüz kırk adet Ti disk $(10 x 3 \mathrm{~mm})$ yüksekliğinde olacak şekilde Ti bloklardan kazınarak hazırlandı ve akril reçine içerisine gömüldü. Rastgele olarak 2'ye ayrılan Ti disklerin yarısına $110 \mu \mathrm{m} \mathrm{Al}_{2} \mathrm{O}_{3}$ ile kumlama işlemi yapıldı, yarısına herhangi bir yüzey işlemi uygulanmadı. Hem kumlanmış hem de yüzey işlemsiz olan bu iki grup da 5 alt gruba ayrıldı. a) Panavia SA Cement (Kuraray) b) Clearfil SE Bond (Kuraray) + Panavia SA Cement (Kuraray) c) Rely X U-200 (3M-Espe) d) Single bond Universal + Rely X U-200 (3M-Espe) and Mis Crown Set Cement (MIS). RS’ler özel bir kalıpla $4 \mathrm{~mm}$ çapında ve $2 \mathrm{~mm}$ kalınlıkta olacak şekilde Ti disklerin ortasına yerleştirildi. Sonrasında her grup kendi içerisinde yaşlandırma uygulanıp uygulanmamasına göre 2 alt gruba daha ayrıldı. Makaslama bağlanma dayanımı testleri $1 \mathrm{~mm} / \mathrm{dk}$ hızla yapıldı. Veriler one-way ANOVA ve Tukey HSD testi kullanılarak istatistiksel olarak analiz edildi.

Bulgular: Gruplar arasında anlamlı bir fark vardır $(\mathrm{p}<0,05)$. Tüm rezin siman grupları için kumlanmış ve bonding ajan uygulanmış gruplar, yüzey işlemsiz gruplara göre daha yüksek bağlanma dayanımı göstermiştir $(\mathrm{p}<0,05)$. Kumlama + Clearfil SE Bond (Kuraray) + Panavia SA Cement (yaşlandırma uygulanmamış) grup en yüksek bağlantı değerini $(182,761 \pm 41,55)$ gösterirken,

Address for Correspondence: Gülsüm SAYIN ÖZEL, İstanbul Medipol University Faculty of Dentistry, istanbul, Turkey

E-mail: gozel@medipo.edu.tr ORCID ID: orcid.org/0000-0001-8833-5259 
(15.32 \pm 7.38$)$ non-treated (thermocycled) groups had the lowest values.

Conclusion: Sandblasting and bonding agents can improve bond strength. The thermocycling period decreased the bond strength values for all groups.

Keywords: Titanium, resin cement, thermocycle, bond strength, semipermanent cements, methacryloyloxydecyl dihydrogen phosphate
MIS Cement $(17,681 \pm 9,33)$ ve Panavia SA Cement $(15,32 \pm 7,38)$ yüzey işlemsiz (yaşlandırma uygulanmış) gruplar en düşük değerleri göster-miştir.

Sonuç: Kumlama ve bonding ajan uygulaması bağlanma dayanımı arttırmıştır. Isıl döngü ile yaşlandırma tüm gruplar için bağlantı değerlerini düşürmüştür.

Anahtar Sözcükler: Titanyum, rezin siman, termal siklus, bağlantı dayanmı, semipermanent simanlar, MDP

\section{Introduction}

The durability of the connection between the prosthetic superstructure and implant is an essential factor for the longevity of implant-supported fixed denture prostheses (FDPs). This integrity is achieved by either cement or screw retention, which has advantages and disadvantages compared with one another (1). In today's dental practice, the choice of cement versus screw retention of implant-supported FDPs mostly depends on the clinicians' experience and preference with respect to the clinical situation (2).

One advantage of cement-retained implant-supported FDPs is the compensation of improperly placed implants. Especially in the anterior region, it is often impossible to manage aesthetics due to the visibility of the screw access hole (3). Moreover, it is observed that clinicians prefer cemented implant restorations because of their lower complication rate and higher fracture resistance of veneering porcelain $(4,5)$. The situation becomes more challenging if the basic mechanical parameters are not optimum as well, such as reduced abutment/restoration interface and over tapered abutment due to the interarch tooth relations, especially for a single implant-retained crown, which might probably result in decementation, although permanently cemented. However, it is often preferred to make temporary cementation for cement-retained FDPs to maintain retrievability without damage to abutment or implant. However, temporary cementation might result in debonding, especially for restoring reduced abutments because of poor physical properties such as decreased tensile strength and increased solubility $(6,7)$. According to this problem, using permanent cements, including polycarboxylate cement and self-adhesive resins, seems appropriate for cementing fixed implant-supported prostheses due to their high retentive values and lower retention loss risk $(8,9)$. Several studies have also reported the unexpectedly high bonding values of polycarboxylate cement with Titanium (Ti) structures and indicated that some dental cements, including glass ionomer and polycarboxylate, alter the protective Ti oxide layer, resulting in colour changes (10). Even the instructions for using one polycarboxylate cement state that a discoloration effect may result when used with Ti. Thus, it is necessary to use resin cement (RC) for Ti cementation, especially when applying Ti to new areas for aesthetics, such as two-component abutments.

To get the advantages of both cementation types, semipermanent cements that provide the reduction of retention by using petroleum jelly or acrylic with polyurethane resin are advised by various manufacturers, particularly for cementing implantsupported crowns for adequate retention and easy restoration removal $(11,12)$. For both semipermanent and permanent cement types, surface treatments are an important effect for clinical longevity. Several studies about the bond strength of $\mathrm{Ti}$ and the effect of different surface treatments were published in the literature (13-15). Micromechanical and chemical bonding effects were compared with these studies (14). Sandblasting with $\mathrm{Al}_{2} \mathrm{O}_{3}$ particles is the most commonly used method for micromechanical retention promotion and chemical bondings, and it can be achieved by both bonding mechanisms, such as silica coating systems (coJet and Rocatec) and metal primers $(16,17)$. Several surface treatment combinations are possible, so studies investigate the effects of different cementation type protocols. But there are no guidelines on the most appropriate luting procedure between the Ti-RC bond strengths.

Thermocycling can simulate the effect of destructive oral conditions with temperature changes and masticatory forces (18). Therefore, this study aimed to evaluate and compare the effect of surface treatments on shear bond strength (SBS) of two self-adhesive RCs and one semipermanent cement to Ti surfaces before and after thermocycling. The null hypothesis tested was that the RCs tested provide similar bond strength to the nontreated Ti surfaces and the surface modification of Ti enhanced the bond strength values for all types of RCs.

\section{Methods}

A total of $240 \mathrm{Ti}$ discs (10 $\mathrm{mm}$ in diameter and $3 \mathrm{~mm}$ in height) were fabricated and embedded in acrylic resin blocks. A total of 20 groups were planned for this study, with $n=12$. Firstly, $240 \mathrm{Ti}$ discs were randomly divided into two groups; half of the specimens were sandblasted with $110 \mu \mathrm{m} \mathrm{Al}_{2} \mathrm{O}_{3}$ particles, and the other half had no surface treatments (non-treated). Both sandblasted and non-treated specimens were divided into five subgroups, which received one of the following surface conditions and self-adhesive RCs: (a) Panavia SA Cement (Kuraray Noritake Dental Inc., Okayama, Japan), (b) Clearfil SE Bond (Kuraray Noritake Dental Inc.) + Panavia SA Cement, (c) RelyX U200 (3M-Espe, MN, USA), (d) Single Bond Universal + RelyX U200 and (e) MIS Crown Set Cement (MIS, Israel). The materials used in this study are listed in Table 1. 


\section{Bonding and Testing Procedures}

The Ti discs were ultrasonically cleaned in 96\% isopropanol for $3 \mathrm{~min}$, followed by air drying. A mould with a $4 \mathrm{~mm}$ diameter and $2 \mathrm{~mm}$ thickness was placed on the central area of each of the Ti surfaces. RCs were applied into the moulds with or without using the relevant bonding agents for the determined subgroups, and the cementation procedures were completed according to the manufacturer's instructions (Figure 1). For the bonding groups, a bonding agent was applied for $10 \mathrm{~s}$, air-dried for $5 \mathrm{~s}$ and lightcured for $20 \mathrm{~s}$ at a $5 \mathrm{~mm}$ distance from the sample's surface and at a $1,200 \mathrm{~mW} / \mathrm{cm}$ intensity (BluePhase curing light, Ivoclar Vivadent, Liechtenstein) for polymerisation. The RC application procedure was the same for all bonding and non-bonding groups, and $\mathrm{RC}$ was applied with the same Teflon mould. The samples were light-cured for $5 \mathrm{~s}$ with the same distance and light source for initial polymerisation. After gently removing the Teflon mould, each side of the RC cylinders was light-cured for $20 \mathrm{~s}$. The bonding process was performed as recommended by the manufacturers. The bonded specimens were stored in distilled water at $37^{\circ} \mathrm{C}$ for $24 \mathrm{~h}$, and subsequently, each group was again divided into two subgroups, according to whether performing thermocycling or not. The thermocycling procedure was set as 5,000 cycles between $5{ }^{\circ} \mathrm{C}$ and $55^{\circ} \mathrm{C}$ (Thermal Cycler Tester, Dental Teknik, Konya, Turkey); the dwell and transfer times were 30 and $10 \mathrm{~s}$, respectively. The SBS tests were performed using a universal testing machine (TSTM 02500, Elista Ltd., Şti., Istanbul, Turkey) at a $1 \mathrm{~mm} / \mathrm{min}$ crosshead speed via a knifeedge rod. The failure loads were in $N$. The failure modes were

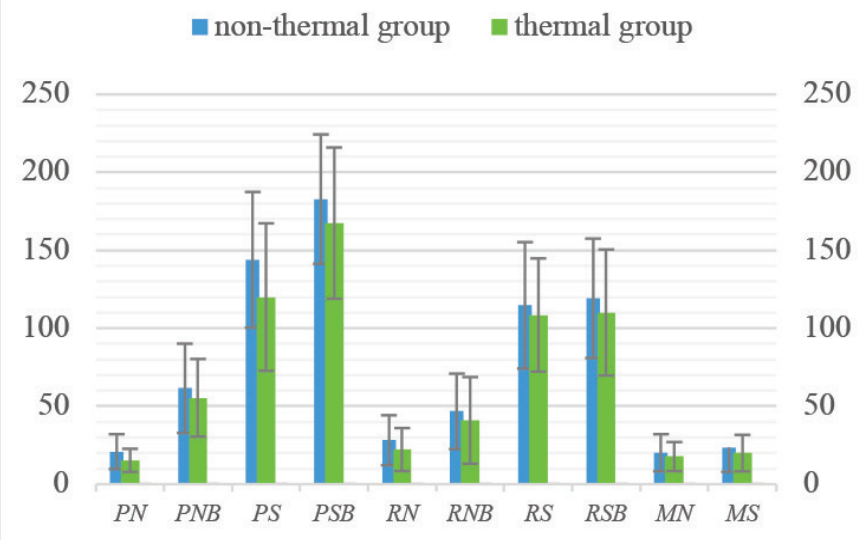

Figure 1. Comparision of the shear bod strength of the groups

Table 1. Materials and surface treatments used in this study

Surface treatments, code

Non-treated, N

Panavia SA Cement, $P$

Clearfil SE Bond (Kuraray) + Panavia SA Cement (Kuraray), PB

RelyX U200 (3M-Espe), R

Single Bond Universal + RelyX U200 (3M-Espe), RB

MK Crown Set Cement (Moredent), M analysed under a stereomicroscope (Olympus SZ40, Olympus Optical Co., Tokyo, Japan) at 40x magnification. The failures were classified as adhesive, cohesive or mixed failure.

\section{Statistical Analysis}

Statistical package SPSS software (version 21.0, SPSS Inc., Chicago, IL, USA) was used at a significance level of $\alpha=0.05$. The Kolmogorov-Smirnov statistical test was performed on the SBS values to evaluate the normal distribution and homogeneity of variances. One-way analysis of variance and Tukey's honestly significant difference test were conducted to determine statistical differences in the SBS values between subgroups, and an independent paired t-test was applied to determine the effect of thermocycling on SBS values.

\section{Results}

Table 2 lists the mean, median and standard deviation of the SBS values and summarises the results of the statistical tests that indicated significant differences between groups $(\mathrm{p}<0.05)$. The differences between the groups are shown in Table 1. Sandblasted and sandblasted + bonding agents provided significantly higher SBS compared with the non-treated and non-treated + bonding agent groups for all RC types $(\mathrm{p}<0.05)$, except for MIS Crown Set Cement $(p>0.05)$. In both non-thermocycled and thermocyled specimens, the sandblasted Clearfil SE Bond + Panavia SA Cement group showed the highest values, whereas the nontreated Panavia SA Cement thermocycled (15.32 \pm 7.38$)$ and non-treated MIS Cement thermocycled $(17.681 \pm 9.33)$ groups showed the lowest values.

The highest SBS values were recorded for the Panavia sandblasted + bonding agents than the other groups after thermal cycling $(\mathrm{p}<0.05)$. However, there was a significant effect on applying bonding agents on sandblasted or non-treated surfaces for only Panavia cement for both thermal and non-thermal conditions $(\mathrm{p}<0.05)$. Additionally, sandblasting alone created higher SBS values for Panavia and RelyX cements compared with applying bonding agents only and non-treated surfaces $(\mathrm{p}<0.05)$. The SBS values of the sandblasted and sandblasted + bonding agent Panavia and RelyX groups were significantly different from those in the non-treated and non-treated + bonded groups $(\mathrm{p}<0.05)$.

Also, for the thermocycled groups, the Panavia SA Cement nontreated group showed the lowest SBS values, followed by the MIS Crown Set Cement non-treated, MIS Crown Set Cement sandblasted and RelyX Cement non-treated groups. But there
$110 \mu \mathrm{m} \mathrm{Al}_{2} \mathrm{O}_{3}$ Sandblasting, $\mathrm{S}$

Panavia SA Cement, $\mathrm{P}$

Clearfil SE Bond (Kuraray) + Panavia SA Cement (Kuraray), PB

RelyX U200 (3M-Espe), R

Single Bond Universal + RelyX U200 (3M-Espe), RB

MK Crown Set Cement (Moredent), M 
were no statistically significant differences between these four groups ( $\mathrm{p}>0.05$ ).

The thermal cycling effect was evaluated and showed that the thermocycling period decreased bond strength values for all groups, but there were no statistically significant differences $(\mathrm{p}>0.05)$.

\section{Failure Mode Analysis}

All failure types of the sequential sandblasted and sandblasted + bonding agents were seen as adhesive. Adhesive failures were also the predominant failure types in all RC types and both thermal and non-thermal conditions. Mixed and cohesive failure modes of RC were evident in the sandblasted and sandblasted + bonding agent groups of Panavia and RelyX cements for both thermal and non-thermal conditions (Table 3). Microscopic image samples for each failure mode are displayed in Figure 2.

\section{Discussion}

The results of this study indicate that RCs that bonded to non-treated Ti surfaces yielded similar SBS values regardless of the cement type and thermocycling procedure. Nevertheless, although the bond strengths of two self-adhesive RCs tested were significantly increased by sandblasting with or without the application of bonding agents, sandblasting did not have any favourable effect on the bond strength of semipermanent cement. Therefore, the null hypothesis was partially accepted. As for the groups with bonding agents solely, no statistical differences were found compared with the non-treated groups

Table 2. Mean and standard deviation of the tested groups

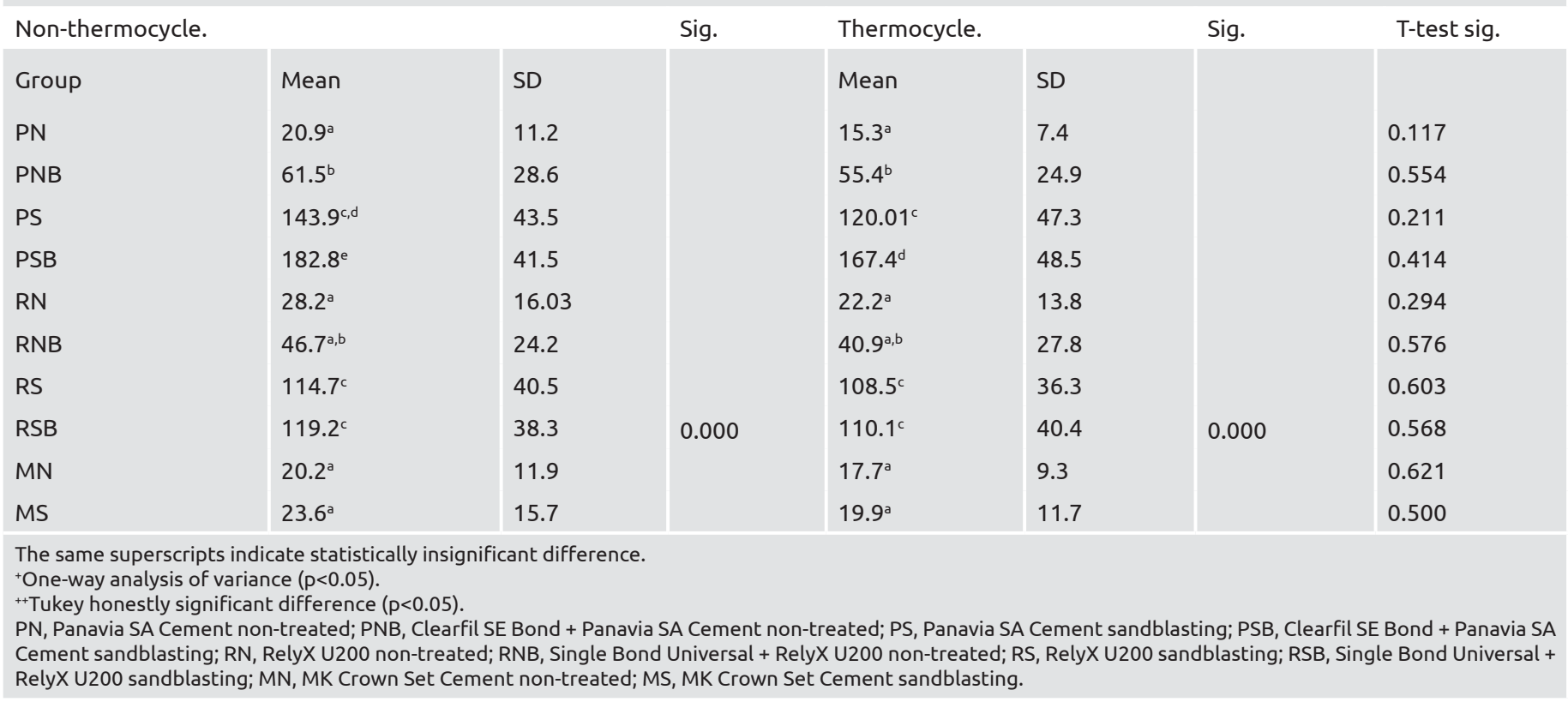

Table 3. Types of bonding fracture failures for each group

\begin{tabular}{|c|c|c|c|c|c|c|}
\hline Failure types & Adhesive & Mixed & Cohesive & Adhesive & Mixed & Cohesive \\
\hline PN & 10 & 2 & - & 12 & - & - \\
\hline PS & 7 & 4 & 1 & 8 & 4 & - \\
\hline PSB & 5 & 5 & 2 & 6 & 5 & 1 \\
\hline RNB & 8 & 4 & - & 9 & 3 & - \\
\hline RS & 8 & 4 & - & 8 & 4 & - \\
\hline RSB & 6 & 5 & 1 & 9 & 3 & \\
\hline MN & 12 & - & - & 12 & - & - \\
\hline MS & 12 & - & - & 12 & - & - \\
\hline
\end{tabular}

PN, Panavia SA Cement non-treated; PNB, Clearfil SE Bond + Panavia SA Cement non-treated; PS, Panavia SA Cement sandblasting; PSB, Clearfil SE Bond + Panavia SA Cement sandblasting; RN, RelyX U200 non-treated; RNB, Single Bond Universal + RelyX U200 non-treated; RS, RelyX U200 sandblasting; RSB, Single Bond Universal + RelyX U200 sandblasting; MN, MK Crown Set Cement non-treated; MS, MK Crown Set Cement sandblasting. 
for RelyX ( $p>0.05)$. Meanwhile, the bond strength values of the sandblasted + bonding agent groups were significantly higher than the bonding agent and non-treated groups $(\mathrm{p}<0.05)$.

The permanent RCs used in this study (Panavia SA Cement and RelyX U200) are dual-cured RCs applied solely and applied with a universal adhesive that belongs to their manufacturers (Clearfil SE Bond and Single Bond, respectively). This bonding agent and Panavia SA Cement contain the monomer 10-methacryloyloxydecyl dihydrogen phosphate (MDP), which was originally designed to bond to metal oxides, although its use has been extended to oxide ceramics (19). It has been stated that MDP-containing RCs are preferable to obtain a chemical bond between the hydroxyl groups of the passive surface and the phosphate ester group of the MDP $(19,20)$. The other cement used in this study is a semipermanent cement, MIS Crown Set Cement, which is advised by the manufacturer due to its high retention properties and easy restoration removal ability. In our study, the bond strength of MIS Crown Set Cement provided the lowest values even for the sandblasted Ti surfaces.

On the other hand, sandblasting of $\mathrm{Ti}$ significantly enhanced the bond strength of Panavia SA Cement and RelyX U200 than that of MIS Cement. Therefore, it is sensible to prefer sandblasting of $\mathrm{Ti}$ abutments and using permanent cements with bonding agents including MDP for reduced abutment/ restoration interface and over tapered abutments in the existence of limited interarch space. After sandblasting, both the debris and metal oxide layer are removed from $\mathrm{Ti}$ alloys. However, immediately afterwards, a thin, stable oxide layer is reproduced, which interacts with the MDP monomer, forming a chemical bond between the dihydrogen phosphate group and metal oxides $(18,21)$. In a study by Koizumi et al. (22), primers containing MDP were determined to be more effective for treating Ti than other primers without MDP. Di Francescantonio et al. (23) stated that the direct application of Panavia F 2.0 to Ti surface without using an adhesive primer provided a favourable bond strength due to the MDP content. Correspondingly, in our
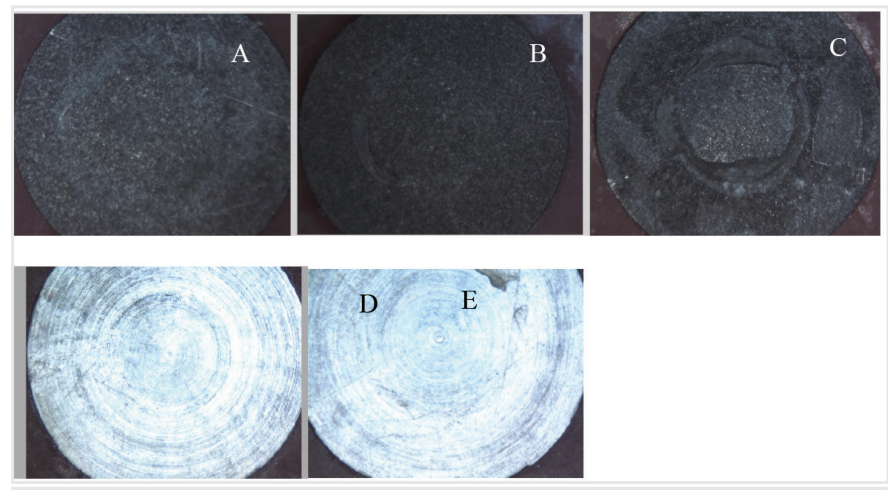

Figure 2. View of failure types; A- Adhesive type for sandblasted surfaces, B-Mixed type for sandblasted surfaces, C- Cohesive type for sandblasted surfaces, DAdhesive type for non-treated surfaces, E- Mixed type for non-treated surfaces study, Panavia samples with or without using a bonding agent (Clearfil SE Bond 2) yielded similar bond strength values as well. But although there were no significant differences between all RC types for the thermocycled non-treated groups ( $p>0.05$ ), the non-treated thermocycled Panavia SA Cement group showed the lowest values among all groups in our results. This situation can be explained by the fact that the MDP content in Panavia SA Cement is not as high as the MDP content in Clearfil SE Bond, which is defined as the gold standard for MDP content. Nevertheless, the Clearfil SE Bond + Panavia SA Cement sandblasting group showed the highest bond strength among all the other groups both before and after thermocycling.

It is well documented in the literature that sandblasting of $\mathrm{Ti}$ surfaces enhanced the bond strength of cemented restorations compared with smooth Ti surfaces (18,24-26). Tsuchimoto et al. (27) also reported that sandblasting of $\mathrm{Ti}$ increased micromechanical interlocking between resin and $\mathrm{Ti}$, particularly when combined with adhesive primers (27). Yanagida et al. noted that the primers containing MDP monomer improved the bonding durability of composite resins to air-abraded $\mathrm{Ti}$ surfaces even after thermocycling (28). Hon et al. (29) compared the effects of five commercially available silane coupling agents for $\mathrm{Ti}-\mathrm{RC}$ adhesion and reported that conditions, especially thermocycling, significantly affected adhesion, but the five silane coupling agents provided similar and clinically acceptable adhesions. In our study, we used bonding agents that also included silane for Panavia and RelyX. Bonding agents are commonly used in clinical practice as they are easily accessible for clinicians. Because of that, we wanted to compare if there is an adhesive effect of bonding agents, including metal primers or silane coupling agents, for Ti surfaces. Our results are also similar to Hon et al. (29), in which silane content bonding agents provide acceptable adhesion.

\section{Study Limitations}

There were some limitations in this study. Firstly, only sandblasting and machined surfaces were used for comparison because sandblasting is clinically the most common surface treatment method for metals, Ti and zirconia. However, various types of surface treatment methods should be investigated for further studies to understand the effects of surface treatments on bond strength to $\mathrm{Ti}$ and select a more proper type of luting cement for clinical applications. Secondly, this study only used bonding agents that contain silane coupling agents, and only $\mathrm{Ti}$ surfaces were used as substrates. Therefore, further investigations are needed to compare metal primers and silane agents with bonding agents for abutment surfaces. Also, different kinds of abutment materials such as zirconia, lithium disilicate and polyeterkethonekethone can be evaluated for future studies.

Based on these findings, it might be clinically helpful to modify the Ti abutments by sandblasting procedures and pay attention to MDP contents while making the selection of not only the primer or self-etch bonding agent but also the adhesive luting cement itself. 


\section{Conclusion}

It can be concluded that there was no effect in respect to bonding to non-treated $\mathrm{Ti}$ surfaces among the cements tested before and after thermocycling. Nonetheless, for the sandblasted $\mathrm{Ti}$ surfaces, the Panavia SA Cement sandblasting, Clearfil SE Bond + Panavia SA Cement sandblasting, RelyX U200 sandblasting and Single Bond Universal + RelyX U200 sandblasting groups provided higher bond strength than the MIS Crown Set Cement sandblasting group. Therefore, clinicians should prefer a higher retention cement strength with the combination of Ti abutment surface modification for specific cases where weak retention is predicted over single cement-retained crowns.

\section{Ethics}

Peer-review: Externally peer reviewed.

\section{Authorship Contributions}

Surgical and Medical Practices: C.A., G.S.Ö., Concept: G.S.Ö., C.A., Design: G.S.Ö., C.A., Data Collection or Processing:G.S.Ö., C.A., Analysis or Interpretation: G.S.Ö., B.S.O.A., Literature Search: B.S.O.A., G.S.Ö., Writing: B.S.O.A., G.S.Ö.

Conflict of Interest: No conflict of interest was declared by the authors.

Financial Disclosure: The authors declared that this study received no financial support.

\section{References}

1. Gervais MJ, Wilson PR. A rationale for retrievability of fixed, implant-supported prostheses: a complication-based analysis. Int J Prosthodont 2007;20:13-24.

2. Vigolo P, Givani A, Majzoub Z, Cordioli G. Cemented versus screwretained implant-supported single-tooth crowns: a 4-year prospective clinical study. Int J Oral Maxillofac Implants 2004;19:260-5.

3. Wittneben JG, Joda T, Weber HP, Brägger U. Screw retained vs. cement retained implant-supported fixed dental prosthesis. Periodontol 2000 2017;73:141-51.

4. Assenza B, Scarano A, Leghissa G, Carusi G, Thams U, Roman FS, et al. Screw-vs cement-implant-retained restorations: an experimental study in the Beagle. Part 1 . Screw and abutment loosening. J Oral Implantol 2005;31:242-6.

5. Torrado E, Ercoli C, Al Mardini M, Graser GN, Tallents RH, Cordaro L. A comparison of the porcelain fracture resistance of screw-retained and cement-retained implant-supported metal-ceramic crowns. J Prosthet Dent 2004;91:532-7.

6. Nematollahi F, Beyabanaki E, Alikhasi M. Cement Selection for Cement-Retained Implant-Supported Prostheses: A Literature Review. J Prosthodont 2016;25:599-606.

7. Kim Y, Yamashita J, Shotwell JL, Chong KH, Wang HL. The comparison of provisional luting agents and abutment surface roughness on the retention of provisional implant-supported crowns. J Prosthet Dent 2006;95:450-5.
8. Ozyllmaz OY. Effect of luting space and cements on retention of implant supported crowns fabricated by laser sintering. Selcuk Dental Journal 2017;4:10-6.

9. Abi-Rached Fde O, Fonseca RG, Haneda IG, de Almeida-Júnior AA, Adabo GL. The effect of different surface treatments on the shear bond strength of luting cements to titanium. J Prosthet Dent 2012;108:370-6.

10. Horasawa N, Marek M. Effect of fluoride from glass ionomer on discoloration and corrosion of titanium. Acta Biomater 2010;6:6626.

11. Bresciano M, Schierano G, Manzella C, Screti A, Bignardi C, Preti G. Retention of luting agents on implant abutments of different height and taper. Clin Oral Implants Res 2005;16:594-8.

12. Heinemann F, Mundt T, Biffar R. Retrospective evaluation of temporary cemented, tooth and implant supported fixed partial dentures. J Craniomaxillofac Surg 2006;34:86-90.

13. Khan AA, Al Kheraif AA, Syed J, Divakar DD, Matinlinna JP. Enhanced resin titanium adhesion with silane primers using tribochemical silica-coating. Dent Mater J 2017;36:111-6.

14. Gehrke P, Alius J, Fischer C, Erdelt KJ, Beuer F. Retentive strength of two-piece CAD/CAM zirconia implant abutments. Clin Implant Dent Relat Res 2014;16:920-5.

15. Taira Y, Yang L, Atsuta M. Comparison of four fluoride etchants in bonding between titanium and a self-curing luting agent. Dent Mater J 2006;25:345-51.

16. Kurt M, Külünk T, Ural C, Külünk Ş, Danişman Ş, Savaş S. The effect of different surface treatments on cement-retained implantsupported restorations. J Oral Implantol 2013;39:44-51.

17. Yanagida H, Matsumura H, Taira Y, Atsuta M, Shimoe S. Adhesive bonding of composite material to cast titanium with varying surface preparations. J Oral Rehabil 2002;29:121-6.

18. Elsaka SE. Effect of surface pretreatments on the bonding strength and durability of self-adhesive resin cements to machined titanium. J Prosthet Dent 2013;109:113-20.

19. Papia E, Larsson C, du Toit M, Vult von Steyern P. Bonding between oxide ceramics and adhesive cement systems: a systematic review. J Biomed Mater Res B Appl Biomater 2014;102:395-413.

20. Casucci A, Osorio E, Osorio R, Monticelli F, Toledano M, Mazzitelli $\mathrm{C}$, et al. Influence of different surface treatments on surface zirconia frameworks. J Dent 2009;37:891-7.

21. Taira Y, Matsumura H, Yoshida K, Tanaka T, Atsuta M. Influence of surface oxidation of titanium on adhesion. J Dent 1998;26:69-73.

22. Koizumi H, Naito K, Ishii T, Yamashita M, Yoneyama T, Matsumura $\mathrm{H}$. Adhesive bonding of Ti-6Al-7Nb alloy and component metals with acidic primers and a tri-n-butylborane initiated resin. J Adhes Dent 2012;14:283-92.

23. Di Francescantonio M, Oliveira MT, Daroz LG, Henriques GE, Giannini M. Adhesive bonding of resin cements to cast titanium with adhesive primers. Braz Dent J 2012;23:218-22.

24. Sahu N, Lakshmi N, Azhagarasan NS, Agnihotri Y, Rajan M, Hariharan R. Comparison of the effect of implant abutment surface 
modifications on retention of implant-supported restoration with a polymer based cement. J Clin Diagn Res 2014;8:239-42.

25. Shayegh S, Salari AM, Ayoubi M, Younesi F. Effect of Three Types of Temporary Luting Cements and Abutment Surface Sandblasting on Retentive Strength of Implant-Supported Fixed Prostheses. J Islam Dent Assoc Iran 2015;27:109-15.

26. Jugdev J, Borzabadi-Farahani A, Lynch E. The effect of air abrasion of metal implant abutments on the tensile bond strength of three luting agents used to cement implant superstructures: an in vitro study. Int J Oral Maxillofac Implants 2014;29:784-90.
27. Tsuchimoto Y, Yoshida Y, Takeuchi M, Mine A, Yatani H, Tagawa $\mathrm{Y}$, et al. Effect of surface pre-treatment on durability of resin-based cements bonded to titanium. Dent Mater 2006;22:545-52.

28. Yanagida H, Tanoue N, Ide T, Matsumura H. Evaluation of two dualfunctional primers and a tribochemical surface modification system applied to the bonding of an indirect composite resin to metals. Odontology 2009;97:103-8.

29. Hon AK, Matinlinna JP, Shibata Y, Miyazaki T, Pow EHN. Evaluation of five silane coupling agents on resin-titanium adhesion. International Journal of Adhesion and Adhesives 2019;90:132-7. 